\title{
Poisoning effect of bismuth on modification behaviour of strontium in LM25 alloy
}

\author{
S FARAHANY*, A OURDJINI, M H IDRIS and L T THAI \\ Materials Engineering Department, Faculty of Mechanical Engineering, UTM Skudai, 81310 Johor, Malaysia
}

MS received 3 January 2011; revised 7 February 2011

\begin{abstract}
Nucleation and growth, temperature measurements and microstructure observations of silicon phase are presented for strontium modified $\mathrm{Al}-7 \% \mathrm{Si}$ (LM25) cast alloy treated with bismuth. The results show that addition of bismuth in strontium modified alloys may have a poisoning effect resulting in lost modification of the silicon phase. With increasing $\mathrm{Bi} / \mathrm{Sr}$ ratio, thermal analysis measurements showed that the eutectic growth temperature increased remarkably to $573^{\circ} \mathrm{C}$ and recalescence decreased to $0 \cdot 2^{\circ} \mathrm{C}$ and the morphology of silicon displayed the same flakelike structure as in the unmodified alloys. Microstructural observation showed that a minimum $\mathrm{Bi} / \mathrm{Sr}$ ratio of 1.2 which is equivalent to a $\mathrm{Sr} / \mathrm{Bi}$ ratio of 0.43 is required for effective strontium modification and neutralization of the poisoning effect of bismuth.
\end{abstract}

Keywords. Thermal analysis; bismuth; modification; aluminium alloy.

\section{Introduction}

Al-Si cast alloys provide an extensive range of properties such as high strength to weight ratio, good corrosion resistance, and excellent castability which are suitable for automotive and aerospace industries. Flake/plate-like silicon observed in conventional $\mathrm{Al}-\mathrm{Si}$ castings imparts relatively poor mechanical properties, especially ductility. Cast Al-Si alloys are usually treated with strontium $(\mathrm{Sr})$ or sodium $(\mathrm{Na})$ to improve their mechanical properties, a process known as modification which results in a change in the eutectic silicon from flake-like into a fibrous morphology (Hosch et al 2009). Recently, there has been a great deal of research on the effect of possible interactions between these modifiers and other elements present in the melt. Research studies have reported chemical neutralization or poisoning effect on the effectiveness of sodium and strontium in modifying the silicon (Wang and Gruzleski 1990; Pan et al 1994; Loper et al 2001; Golbahar et al 2007). To obtain the desired microstructures that will produce enhanced mechanical properties, knowledge of the effect of such elements on the strontium modification of silicon is essential.

Bismuth addition to aluminium alloys is to improve their machinability and produce free-machining alloys. Furthermore, Bi renders cast components suitable for applications where hard extruded and machined parts are required. It also promotes chip breaking and helps tool lubrication and may also be added to aluminum-magnesium alloys to counteract

\footnotetext{
*Author for correspondence (saeedfarahany@gmail.com, fsaeed2@live.utm.my)
}

the detrimental effect of sodium on hot cracking (Talbot and Ransley 1997).

Pillai and Anantharaman (1968) reported that bismuth could play a role as silicon modifier whereas recently, it has been found that bismuth refines rather than modifies the eutectic flake structure (Farahany et al 2011). It has been reported that with a $\mathrm{Sr} / \mathrm{Bi}$ ratio above 0.45 the structure was modified in $319 \mathrm{Al}$ alloy (Machovec et al 2000). In addition, it has been reported that with $0.1 \% \mathrm{Bi}$ addition, the modification effect of $\mathrm{Sr}$ was eliminated in A356 alloy (Cho and Loper 2000). Study on 319 alloy also indicated that the modification effect of strontium was found to diminish with $\mathrm{Bi}$ addition up to 0.225 wt.\% Bi (El-Hadad et al 2004), whilst adding $0.5 \mathrm{wt} . \% \mathrm{Bi}$ to the modified and grain-refined $\mathrm{Al}-$ $10 \cdot 8 \% \mathrm{Si}$ alloy led to coarsening of the eutectic Si particles (Mohamed et al 2009).

Metallography has long been established as the main methodology for the observation and examination of phase transformation during solidification. Nevertheless, this process is time consuming and the results are related to area sample selection and sample preparation. On the other hand, thermal analysis has been gaining increasing acceptance in many aluminium foundries as a fast method, on-line process control, non-destructive and quantitative technique for microstructure control (Apelian et al 1984; Djurdjevic et al 2001; Emadi et al 2005) which can be used prior to casting (Apelian et al 1984; Heusler and Schneider 2002).

The purpose of the present study is to report nucleation and growth temperature measurements in strontiummodified LM25 cast aluminum alloy treated with bismuth and to relate them to possible poisoning effect of bismuth on strontium modification. 


\section{Experimental}

A commercial grade LM25 (Al-7\% Si -0.4\%Mg) was melted in electrical resistance furnace under argon and the temperature of melt was kept at $750^{\circ} \mathrm{C}$ for complete homogenization. Upon thermal equilibrium, strontium was added as an $\mathrm{Al}-10 \mathrm{Sr}$ master alloy and after some time of dissolution and homogenization, pure bismuth was added in the form of metallic shots at different concentrations. After stirring for about $30-40 \mathrm{~s}$, the molten alloy was poured at a temperature of $730 \pm 5^{\circ} \mathrm{C}$ into two different moulds: pre-heated ceramic and pre-heated stainless steel mould, in order to achieve slow and fast cooling rates. Chemical compositions of alloys used in the present study analysed by glow discharge spectroscopy (LECO GDS-850A) are shown in table 1.

Thermal analysis was carried out by attaching a highly sensitive $K$-type thermocouple located in the middle of the ceramic mould which solidified at a slower rate to determine the characteristic temperatures of nucleation and growth during solidification. Prior to all temperature measurements, the thermocouples were calibrated to ensure accurate and precise reading and recording. The temperature-time data was obtained using EPAD-TH8-K high speed data acquisition system linked to a computer at a dynamic rate of $100 \mathrm{~Hz} / \mathrm{ch}$, as shown in figure 1. Flexpro.8 data analysis software was used for smoothing the curves and plotting cooling, first and second derivative curves and also for extracting characteristic temperatures. Typical cooling, first derivative and second derivative curves of LM25 alloy based on thermal analysis for a ceramic mould are as shown in figure $2 \mathrm{a}$. The second derivative curve was used in this work as a precise indicator of the nucleation temperature $\left(T_{\mathrm{N}}\right)$ of transformation. A turning point in the second derivative shows the precise moment when the cooling rate $(\mathrm{d} T / \mathrm{d} t)$ shifts upwards, indicating the start of latent heat evaluation and $T_{\mathrm{N}}$. The eutectic arrest area and the method to define the three main points $\left(T_{\mathrm{N}}, T_{\min }\right.$ and $\left.T_{\mathrm{G}}\right)$ are shown in figure $2 \mathrm{~b}$. The cooling rate obtained from these curves was found to be $0.7^{\circ} \mathrm{C} / \mathrm{s}$ and $8^{\circ} \mathrm{C} / \mathrm{s}$ in ceramic and stainless steel moulds, respectively.

Samples for metallography were sectioned horizontally which was located at the tip of thermocouple. These samples were first mounted, ground with SiC papers of different grades and then polished. Deep etching by solution of $10 \%$ hydrochloric acid and $90 \%$ ethanol was used to examining the change in morphology and spatial distribution of the silicon eutectic due to $\mathrm{Bi}-\mathrm{Sr}$ interaction so as to reveal the 3D morphology. The microstructures were analysed using

Table 1. Designations and chemical compositions of experimental alloys (wt.\%).

\begin{tabular}{lcccccc}
\hline Alloy code & $\mathrm{Si}$ & $\mathrm{Mg}$ & $\mathrm{Sr}$ & $\mathrm{Bi}$ & $\mathrm{Al}$ & Bi/Sr ratio \\
\hline Base & 6.783 & 0.390 & - & - & remaining & - \\
Sr mod & 6.925 & 0.413 & 0.004 & - & remaining & - \\
BiSr10 & 7.003 & 0.400 & 0.018 & 0.018 & remaining & 1 \\
BiSr12 & 7.100 & 0.421 & 0.036 & $0 \cdot 045$ & remaining & 1.2 \\
BiSr17 & 6.690 & 0.395 & 0.010 & 0.017 & remaining & 1.7 \\
BiSr23 & 6.784 & 0.413 & 0.016 & 0.037 & remaining & 2.3 \\
BiSr40 & 7.011 & 0.414 & 0.004 & 0.016 & remaining & 4 \\
BiSr85 & 7.103 & 0.400 & 0.002 & 0.017 & remaining & 8.5 \\
\hline
\end{tabular}

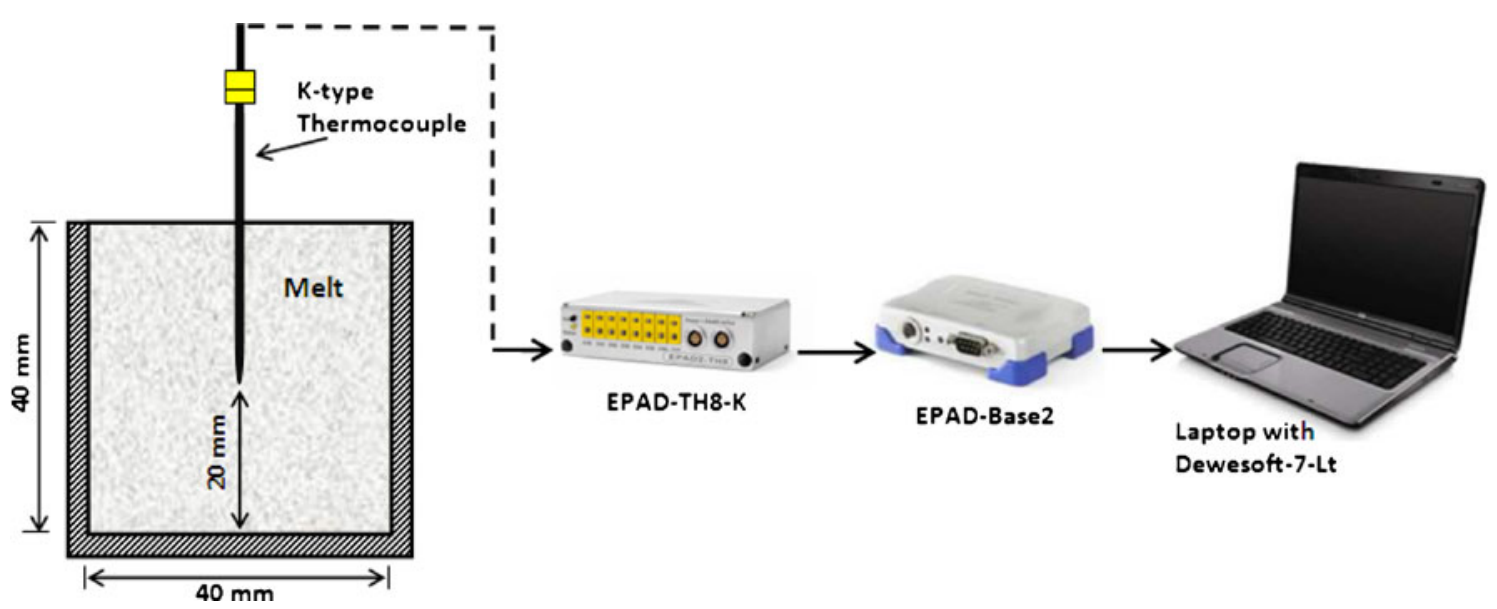

Figure 1. Thermal analysis set up with ceramic mould and thermocouple. 


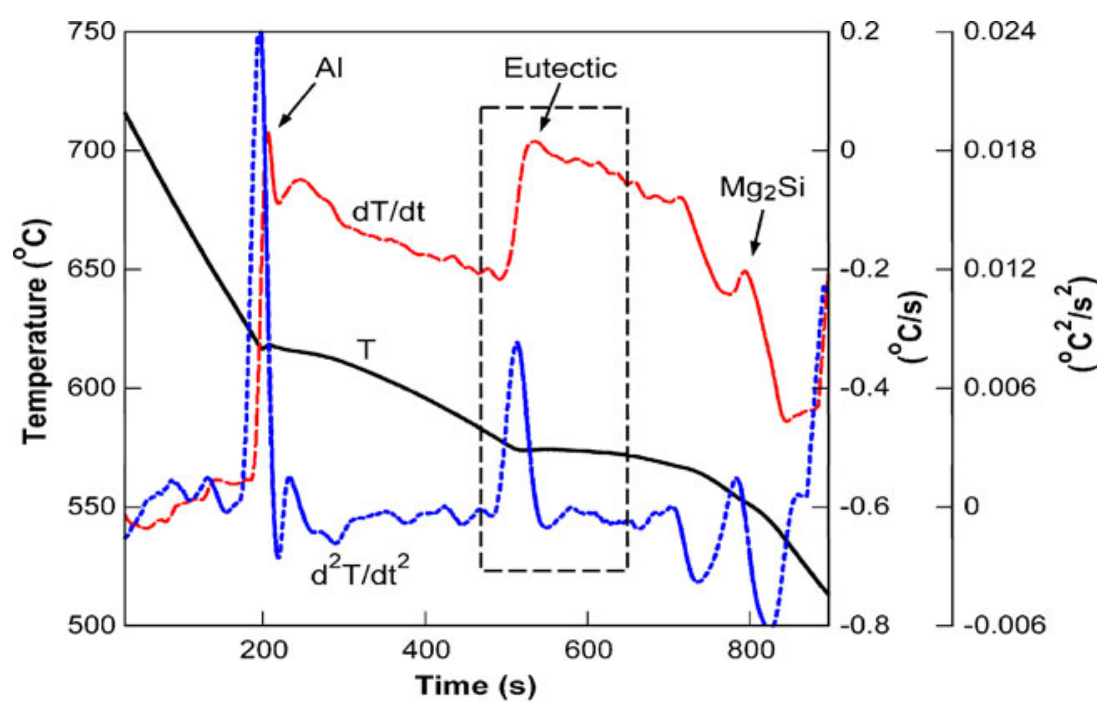

(a)

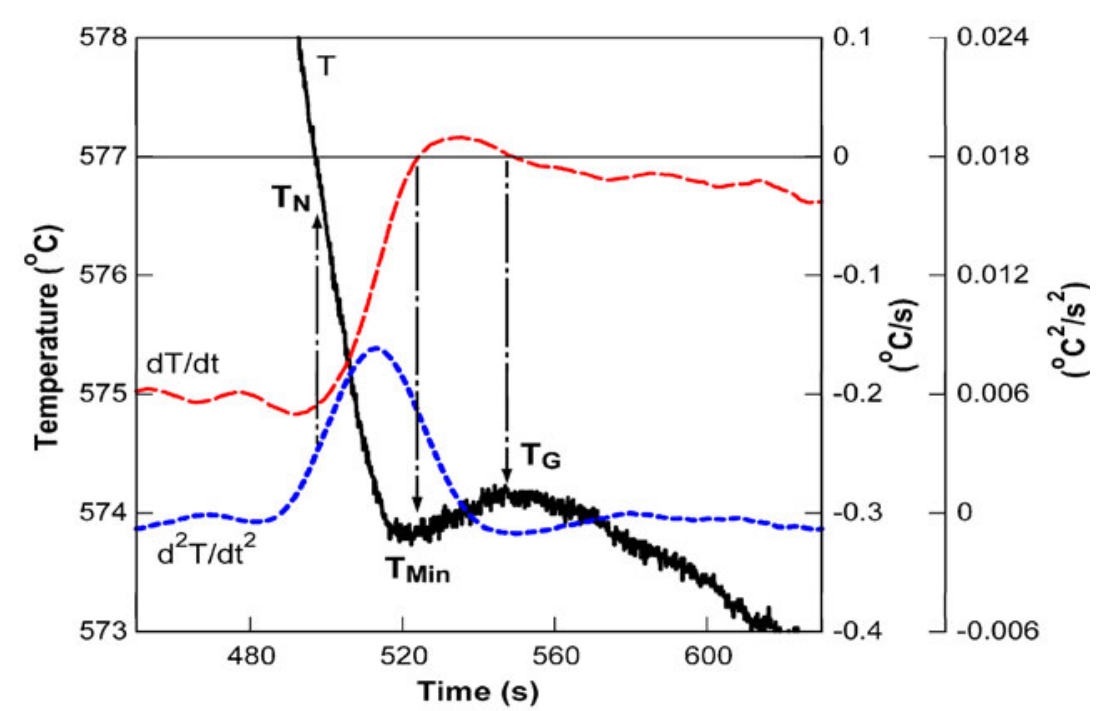

(b)

Figure 2. (a) Cooling curve of LM25 with its corresponding 1st and 2nd derivative curves, (b) magnified highlighting of eutectic arrest area and main extracted points $\left(T_{\mathrm{N}}\right.$, $T_{\min }$ and $T_{\mathrm{G}}$ ).

optical (Olympus BX60F5) and field emission scanning electron microscopy (Supra-35VP, Carl Zeiss) and correlated with the cooling curves obtained from thermal analysis.

\section{Results and discussion}

\subsection{Thermal analysis}

The temperature of eutectic nucleation $\left(T_{\mathrm{N}}\right)$, minimum temperature $\left(T_{\min }\right)$ and eutectic growth temperature $\left(T_{\mathrm{G}}\right)$ were measured from the cooling curves of each sample. The nucleation temperature, $T_{\mathrm{N}}$, is identified as the point where the cooling curve starts to bend. $T_{\min }$ and $T_{\mathrm{G}}$ are defined as the minimum and maximum reaction temperatures during and after recalescence, respectively.

Based on thermal analysis data, the cooling curves were plotted for each alloy condition. Figure 3 shows eutectic arrest in untreated and Sr-modified LM25 which depicts that the modification treatment is accompanied by a decrease in $T_{\mathrm{G}}$. In the present study, addition of $0.004 \mathrm{wt} \% \mathrm{Sr}$ was found to cause around $4^{\circ} \mathrm{C}$ depression in the eutectic growth temperature (from $574 \cdot 2^{\circ} \mathrm{C}$ to $570 \cdot 2^{\circ} \mathrm{C}$ ). It has been established that modification of eutectic Si in Al-Si cast alloy is associated with depression in the value of $T_{\mathrm{G}}$ (Elliot 1983; Gruzleski and Closset 1990). In addition, it has also been reported that silicon modification due to the addition of strontium has a correlation with the depression of the eutectic 


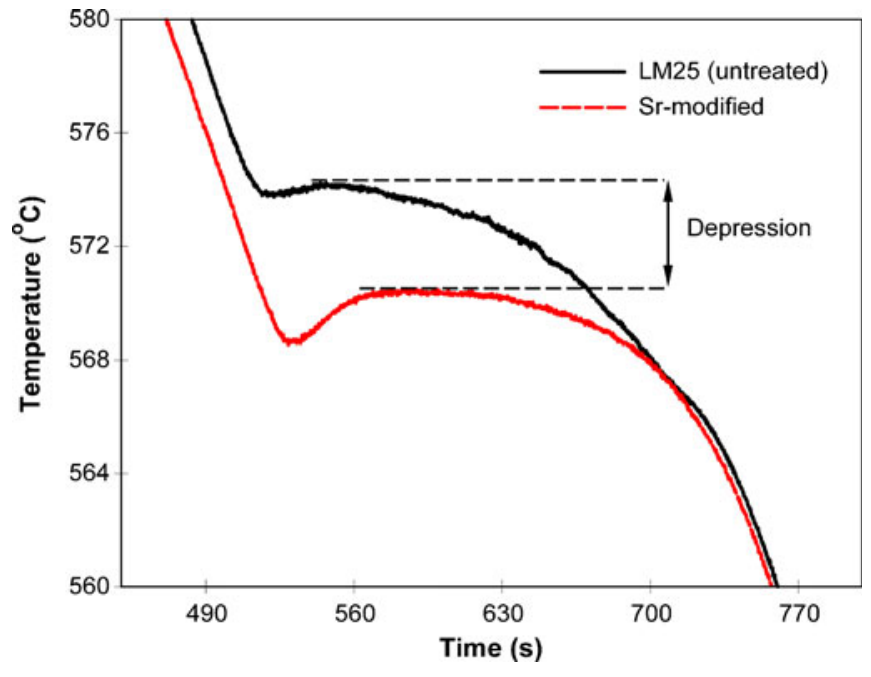

Figure 3. Cooling curve of LM 25 in untreated and Sr-modified conditions around eutectic arrest.

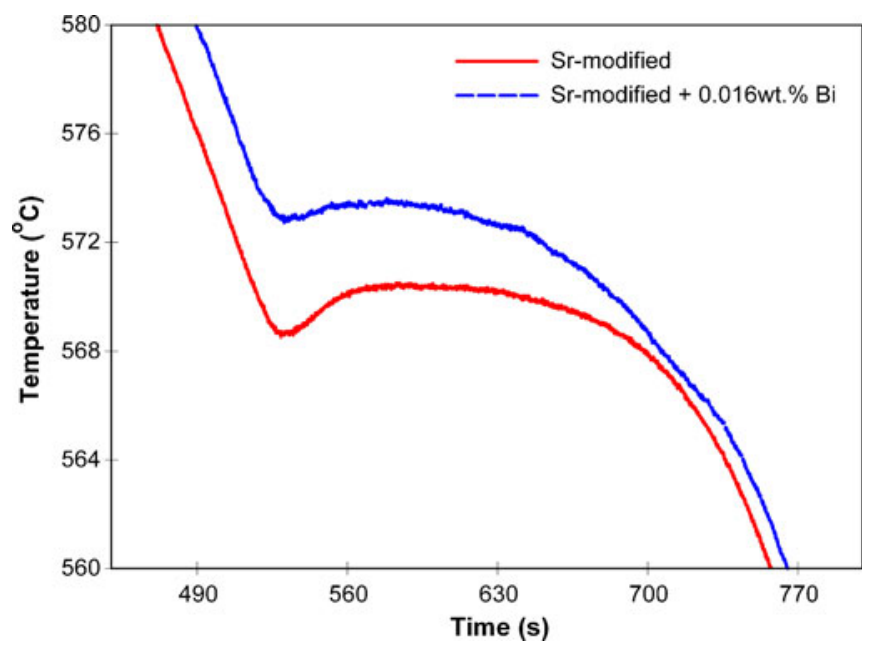

Figure 4. Cooling curve of Sr-modified with 0.016 wt.\% Bi addition.

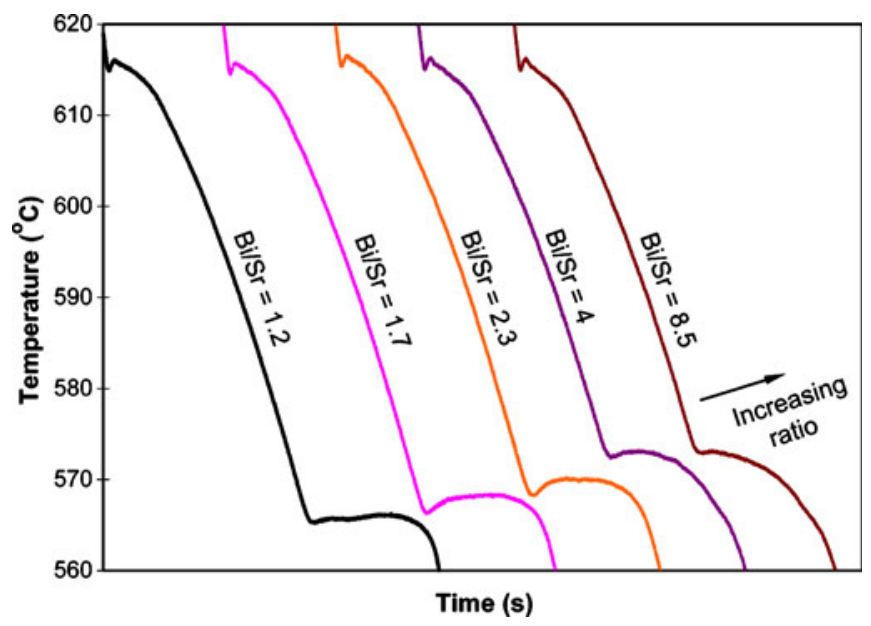

Figure 5. Cooling curve of samples with various $\mathrm{Bi} / \mathrm{Sr}$ ratios in ceramic mould (cooling curves have been displaced along time axis).
Table 2. Nucleation $\left(T_{\mathrm{N}}\right)$, minimum $\left(T_{\min }\right)$, growth temperature $\left(T_{\mathrm{G}}\right)$ and eutectic recalescence.

\begin{tabular}{llccc}
\hline Label & $T_{\mathrm{N}}\left({ }^{\circ} \mathrm{C}\right)$ & $T_{\min }\left({ }^{\circ} \mathrm{C}\right)$ & $T_{\mathrm{G}}\left({ }^{\circ} \mathrm{C}\right)$ & Recalescence $\left({ }^{\circ} \mathrm{C}\right)$ \\
\hline LM25 & $579 \cdot 0$ & $573 \cdot 8$ & $574 \cdot 2$ & $0 \cdot 4$ \\
Sr & $574 \cdot 1$ & $568 \cdot 5$ & $570 \cdot 2$ & $1 \cdot 7$ \\
BiSr10 & 568 & $565 \cdot 0$ & $566 \cdot 2$ & $1 \cdot 2$ \\
BiSr12 & $568 \cdot 6$ & $565 \cdot 6$ & $566 \cdot 2$ & $0 \cdot 6$ \\
BiSr17 & $570 \cdot 4$ & $566 \cdot 3$ & $567 \cdot 9$ & $1 \cdot 6$ \\
BiSr23 & $572 \cdot 7$ & $568 \cdot 3$ & $569 \cdot 9$ & $1 \cdot 6$ \\
BiSr40 & $575 \cdot 0$ & $572 \cdot 2$ & $572 \cdot 9$ & $0 \cdot 7$ \\
BiSr85 & $575 \cdot 8$ & $572 \cdot 9$ & $573 \cdot 1$ & $0 \cdot 2$ \\
\hline
\end{tabular}

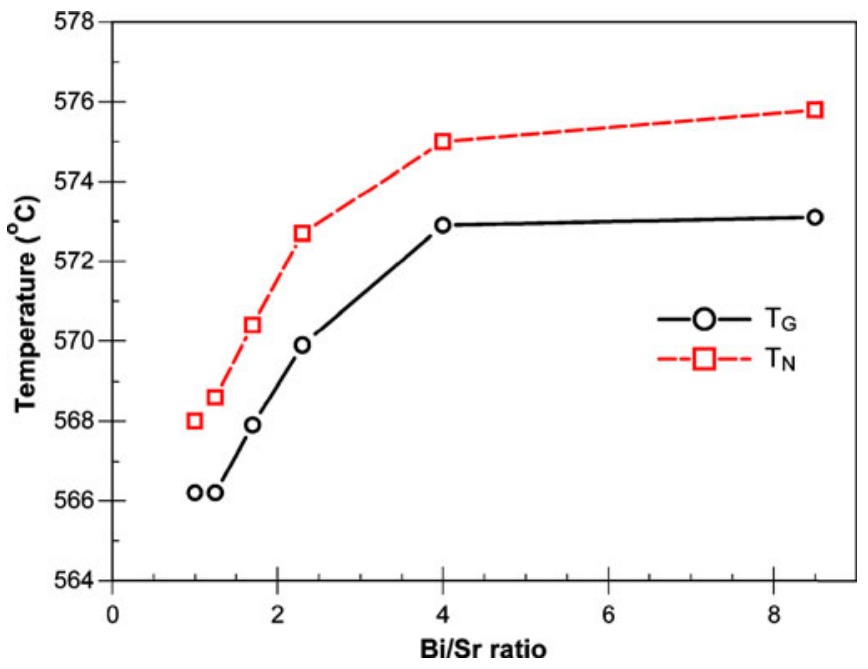

Figure 6. Eutectic nucleation temperature $\left(T_{\mathrm{N}}\right)$ and eutectic growth temperature $\left(T_{\mathrm{G}}\right)$ as a function of $\mathrm{Bi} / \mathrm{Sr}$ ratio.

growth temperature (Djurdjevic et al 2001; Knuutinen et al 2001).

Figure 4 illustrates a comparison of cooling curves obtained for the Sr-modified and combined strontium and $0.016 \mathrm{wt} \% \mathrm{Bi}$. With the addition of bismuth into Srmodified melt, the eutectic growth temperature increased by $\sim 3^{\circ} \mathrm{C}$. This is an indication that the presence of bismuth, even at a low concentration of $0.016 \mathrm{wt} \%$, may have caused the eutectic growth temperature to increase, which based on the discussion above, is directly related to the level of modification of flake silicon. On the other hand, it can be predicted that modification of strontium was lost with the introduction of bismuth into Sr-modified Al-Si alloy melt.

In an attempt to shed more light on the possibility of negative effect of $\mathrm{Bi}$ on $\mathrm{Sr}$ modification, samples with different $\mathrm{Bi} / \mathrm{Sr}$ ratios were prepared. Eutectic nucleation temperature, recalescence and eutectic growth temperature were extracted and determined from the thermal analysis data according to the method described in the previous section. Figure 5 shows cooling curves of samples with various $\mathrm{Bi} / \mathrm{Sr}$ ratios during solidification in ceramic mould. 
A summary of the nucleation $\left(T_{\mathrm{N}}\right)$, minimum $\left(T_{\min }\right)$ and the growth temperatures $\left(T_{\mathrm{G}}\right)$ for all samples is given in table 2. Examination of data in table 2 shows that for all $\mathrm{Bi} / \mathrm{Sr}$ ratios the nucleation temperature is always higher than the growth temperature. The relationship between $T_{\mathrm{N}}$ and $T_{\mathrm{G}}$ with $\mathrm{Bi} / \mathrm{Sr}$ ratio is also plotted in figure 6 where it can be observed that both nucleation and growth temperatures increase to $575.8^{\circ} \mathrm{C}$ and $573.1^{\circ} \mathrm{C}$, respectively with increasing $\mathrm{Bi} / \mathrm{Sr}$ ratio.

The recalescence prior to the eutectic arrest, which is the temperature difference between $T_{\mathrm{G}}$ and $T_{\min }$, is plotted as

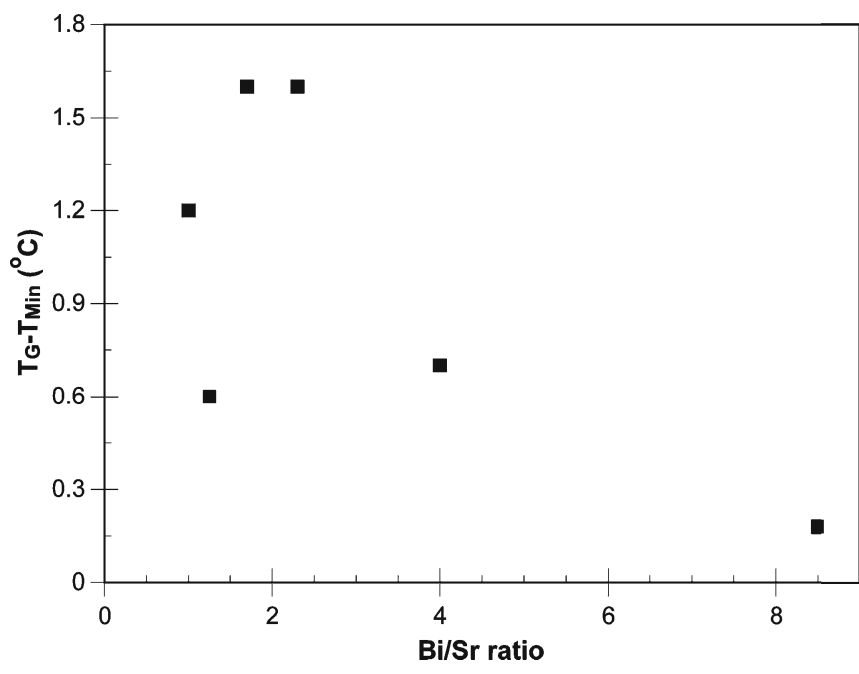

Figure 7. Recalescence as a function of $\mathrm{Bi} / \mathrm{Sr}$ ratio. a function of $\mathrm{Bi} / \mathrm{Sr}$ ratio in figure 7 . The figure shows that the recalescence drops to $0.6^{\circ} \mathrm{C}$ and then stabilizes at $1.6^{\circ} \mathrm{C}$ but decreases gradually with increasing ratio until it reaches a value of $0 \cdot 2^{\circ} \mathrm{C}$ for $\mathrm{Bi} / \mathrm{Sr}$ ratio equal to $8 \cdot 5$. The decrease in the value may be attributed to over-modification. It has been previously reported that the undercooling increases with modification and then falls off, as the structure becomes over-modified (Hegde and Narayan Prabhu 2008).

\subsection{Microstructural analysis}

Figure 8 shows the difference in silicon eutectic structure without and with $\mathrm{Sr}$ or $\mathrm{Bi}$. In the untreated alloy the eutectic silicon displays plate/needle morphology (figure 8a), whereas when the alloy is treated with strontium and bismuth individually, the morphology of eutectic silicon has a fibrous and lamellar structure, respectively (figures $8 \mathrm{~b}$ and c). Figure $8 \mathrm{c}$ provides evidence that $\mathrm{Bi}$ when added individually to $\mathrm{Al}-\mathrm{Si}$ alloy refines rather modifies the silicon structure.

The exact mechanism of modification is still not as well defined. It has been shown that addition elements promote changes in the eutectic nucleation and growth modes (Qiyang et al 1991; Nogita et al 2001). Accordingly, there have been two main theories as to how $\mathrm{Sr}$ or $\mathrm{Na}$ impurity additions cause modification: restricted nucleation theory and restricted growth theory (Qiyang et al 1991; Hegde and Narayan Prabhu 2008). According to restricted nucleation theory there is a possibility that the modifier counteracts
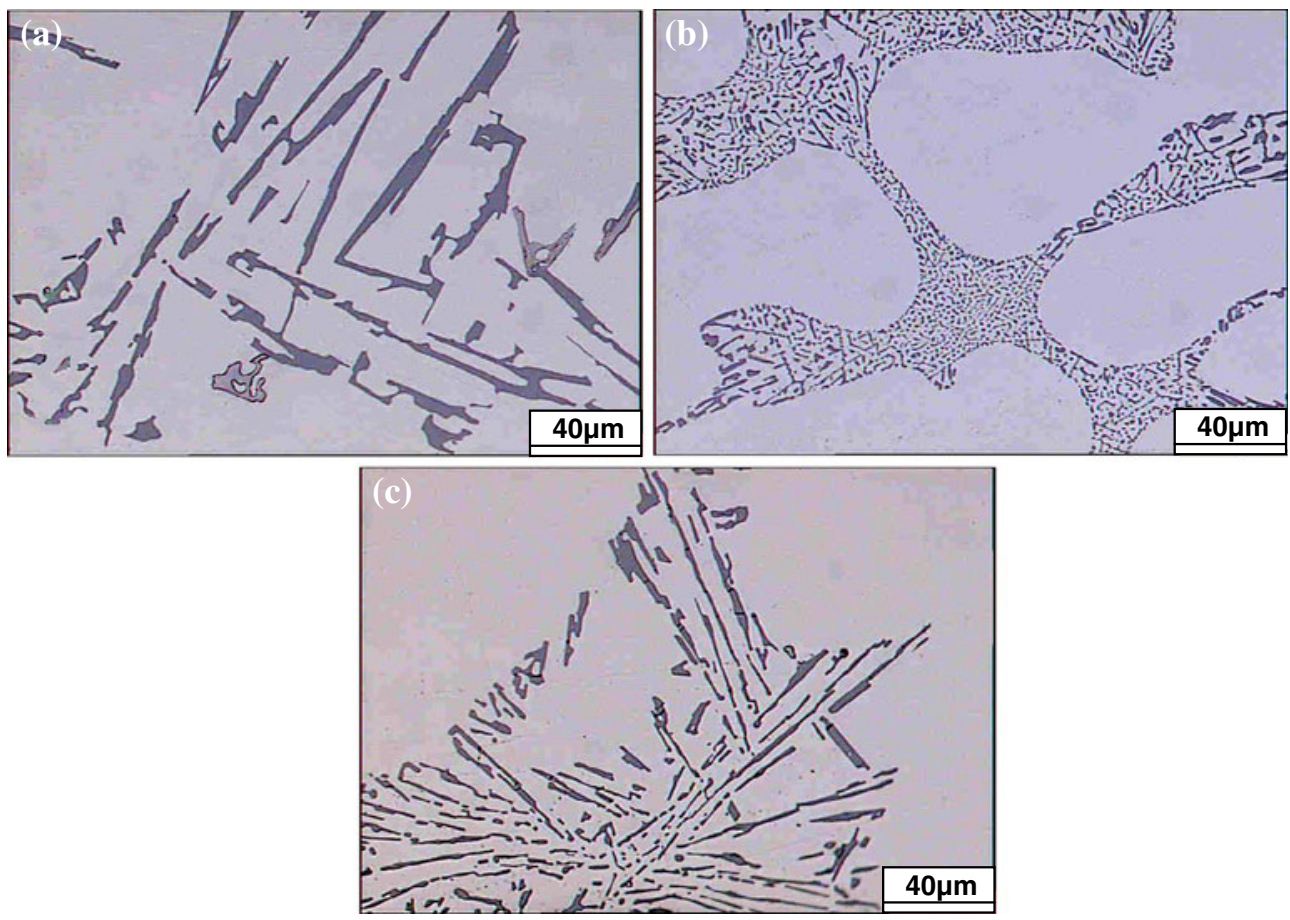

Figure 8. Optical microstructures of (a) LM25, (b) Sr-modified and (c) Bi-treated alloys in ceramic mould. 

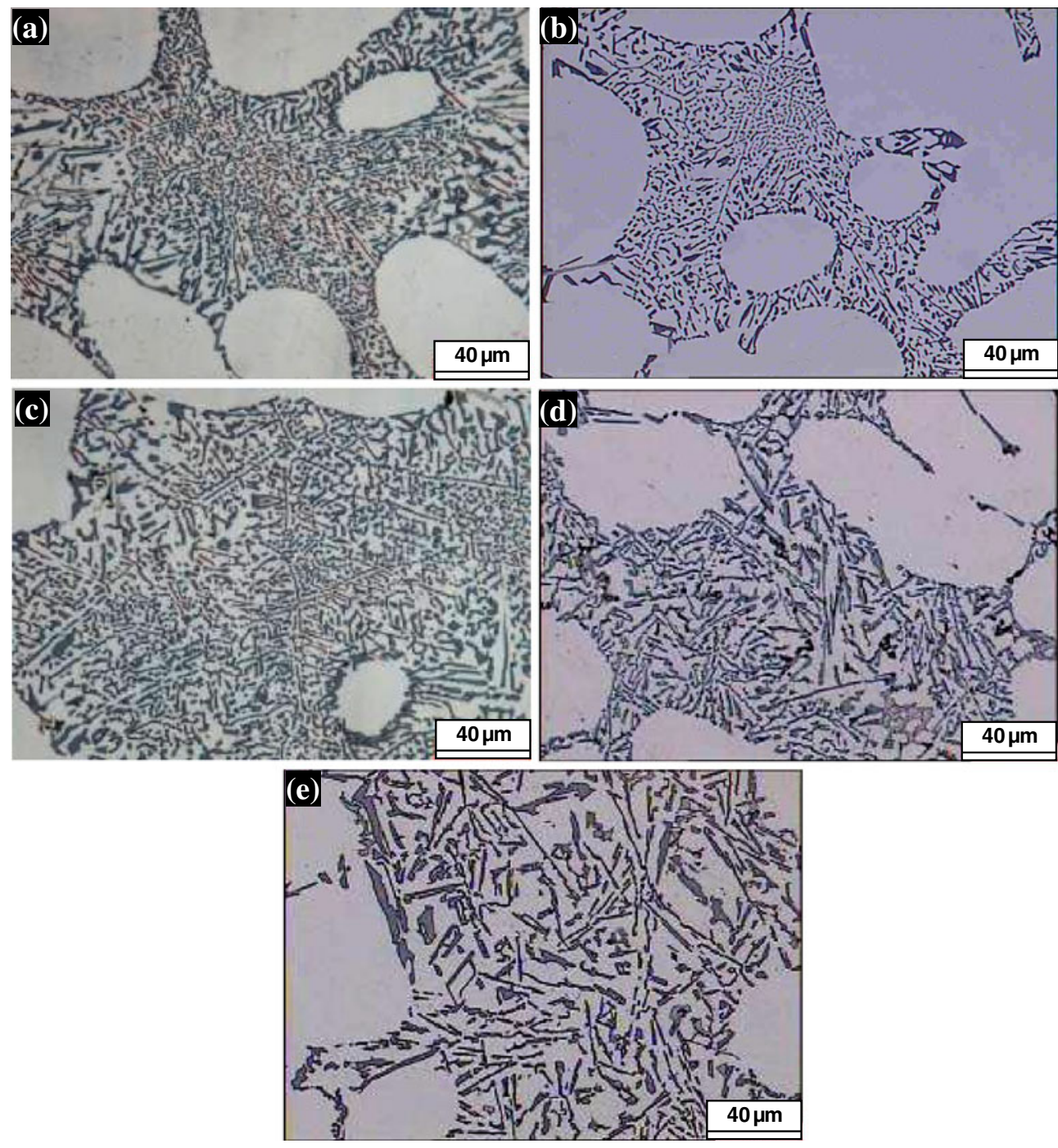

Figure 9. Optical microstructures of specimens with different Bi/Sr ratios: (a) 1.2, (b) 1.7, (c) 2.3, (d) 4 and (e) 8.5 in ceramic mould.

the heterogeneous nuclei of AlP or decreases the diffusion coefficient of $\mathrm{Si}$ in the melt. This will result in increased undercooling prior to eutectic solidification and refining of the eutectic structure. However, it is generally accepted that changes in the growth process rather than in nucleation are responsible for the change in silicon from flake to fibrous morphology. TEM studies of Lu and Hellawell showed that Sr-modified fibres are heavily twinned and several $\{111\}$ twinning systems can operate in a single fibre (Lu and Hellawell 1987).

Figure 9 shows microstructures of specimens with different $\mathrm{Bi} / \mathrm{Sr}$ ratios in ceramic mould solidified at low cooling rate. There is a significant difference in the eutectic silicon shape when the ratio was increased. Fibrous Si was observed in figures $9 \mathrm{a}, \mathrm{b}$ and $\mathrm{c}$, corresponding to $1.2,1.7$ and 2.3 ratios, whereas coarse flake-like $\mathrm{Si}$ is observed in figure $9 \mathrm{~d}$ and specially figure $9 \mathrm{e}$ at $\mathrm{Bi} / \mathrm{Sr}$ ratios of 4 and $8 \cdot 5$, respectively. It can be seen that fibrous morphology converted to large plate-like as observed in unmodified LM25 in figure 8a with increasing $\mathrm{Bi} / \mathrm{Sr}$ ratio.

In order to obtain more conclusive results on the effect of $\mathrm{Bi}$ on Sr-modified silicon structure, cross-sections of specimens were subjected to deep etching to remove aluminium phase and reveal 3-D morphology of the silicon phase. Indeed, SEM micrographs in figure 10 confirm that the eutectic Si has changed from fibrous to plate-like morphology with increasing $\mathrm{Bi} / \mathrm{Sr}$ ratio. In addition, figure 10a shows the presence of some coarse silicon apart from the modified flakes. However, the ratio is lower than other samples, $\mathrm{Sr}$ concentration is high for modification. As the $\mathrm{Sr}$ increases to $0.036 \mathrm{wt} \%$, the silicon eutectic becomes coarser compared to the specimen with lower Sr content (0.0020.018 wt. $\%$ Sr).

From the solidified specimens in stainless steel mould, similar results were obtained as shown in figure 11 with different $\mathrm{Bi} / \mathrm{Sr}$ ratios. Furthermore, it must be noted that the 

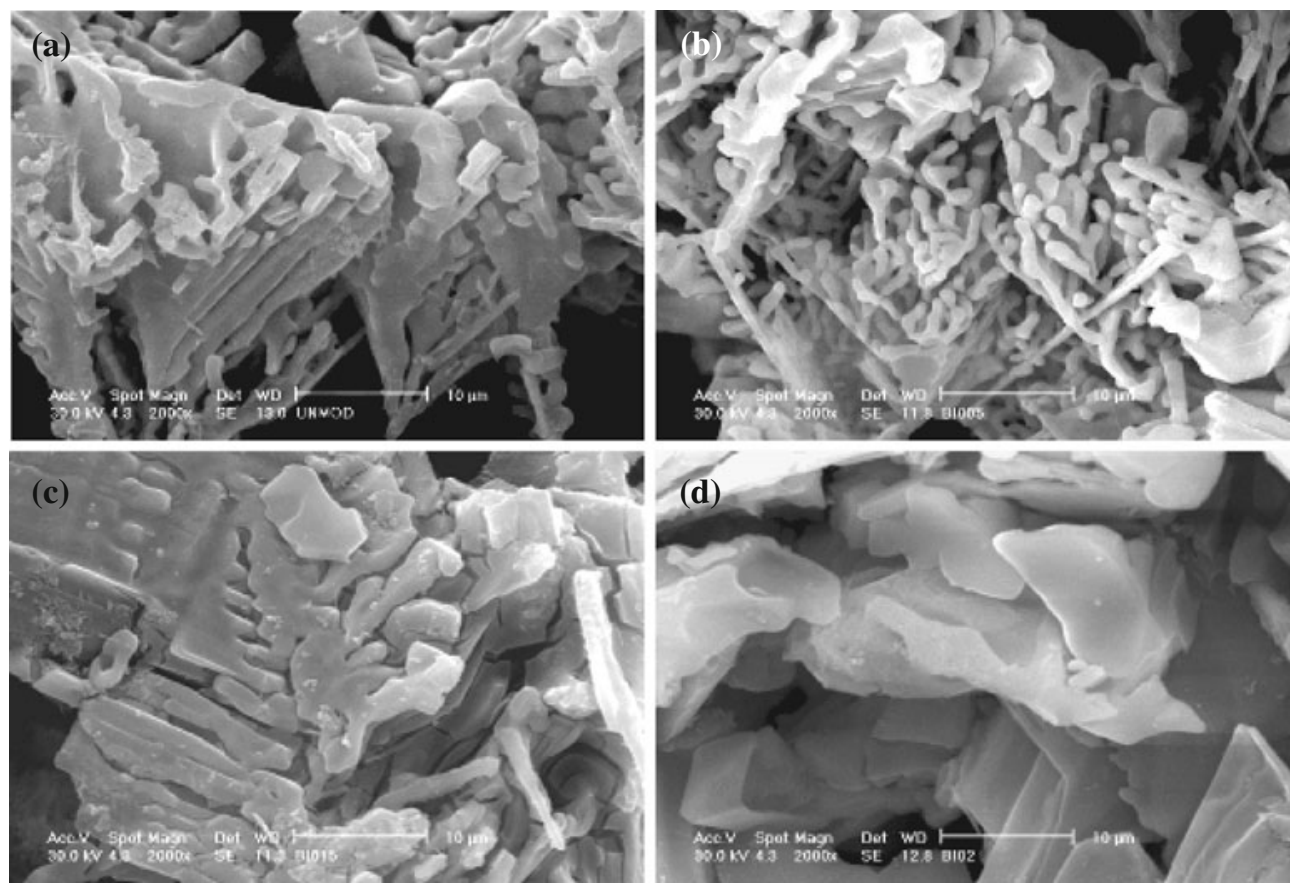

Figure 10. SEM micrographs of specimens with different Bi/Sr ratios: (a) 1·2, (b) 2.3, (c) 4 and (d) 8.5 in ceramic mould.
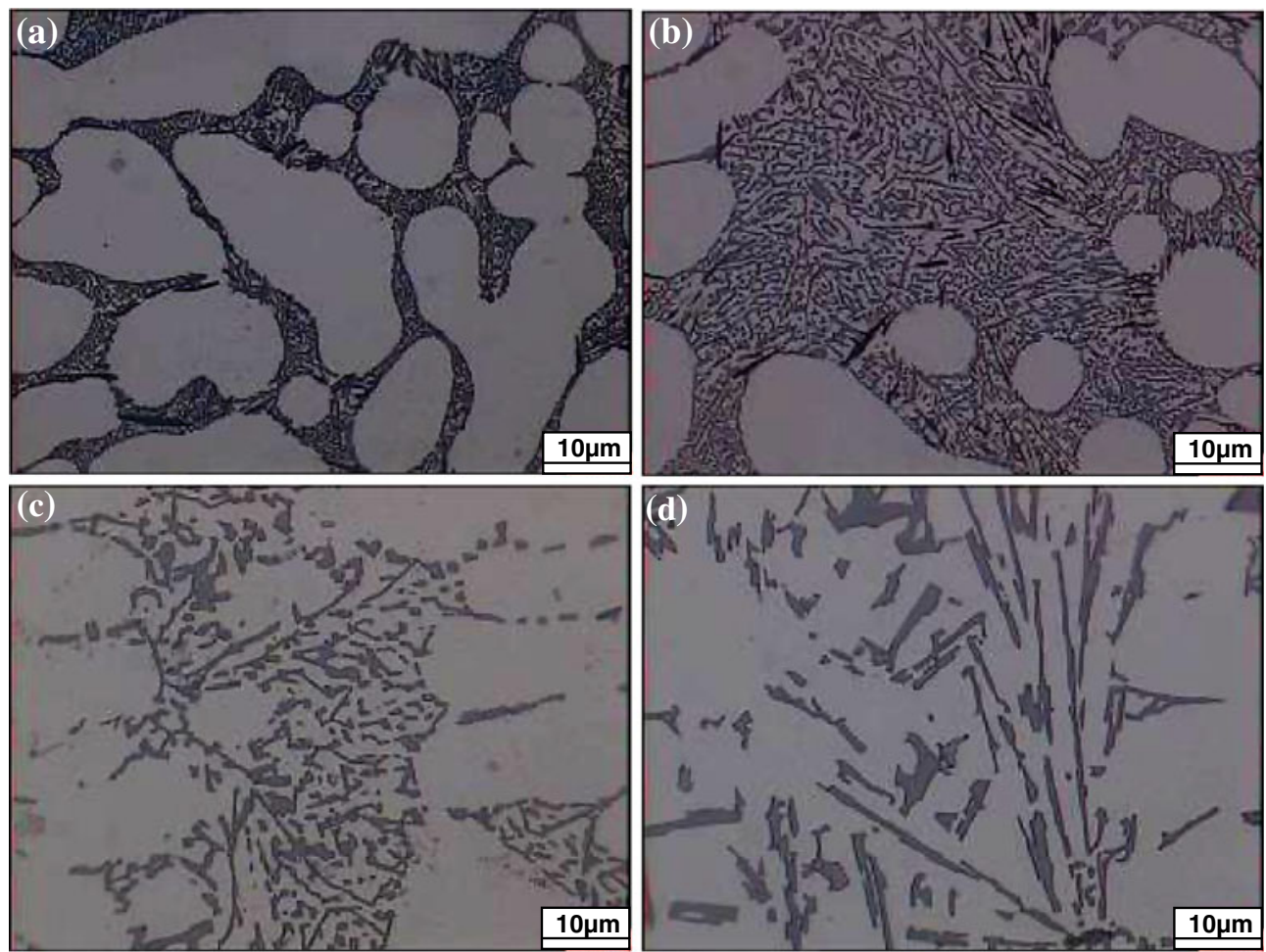

Figure 11. Optical microstructures of specimens with different Bi/Sr ratios: (a) $1 \cdot 2$, (b) $2 \cdot 3$, (c) 4 and (d) 8.5 in stainless steel mould. 

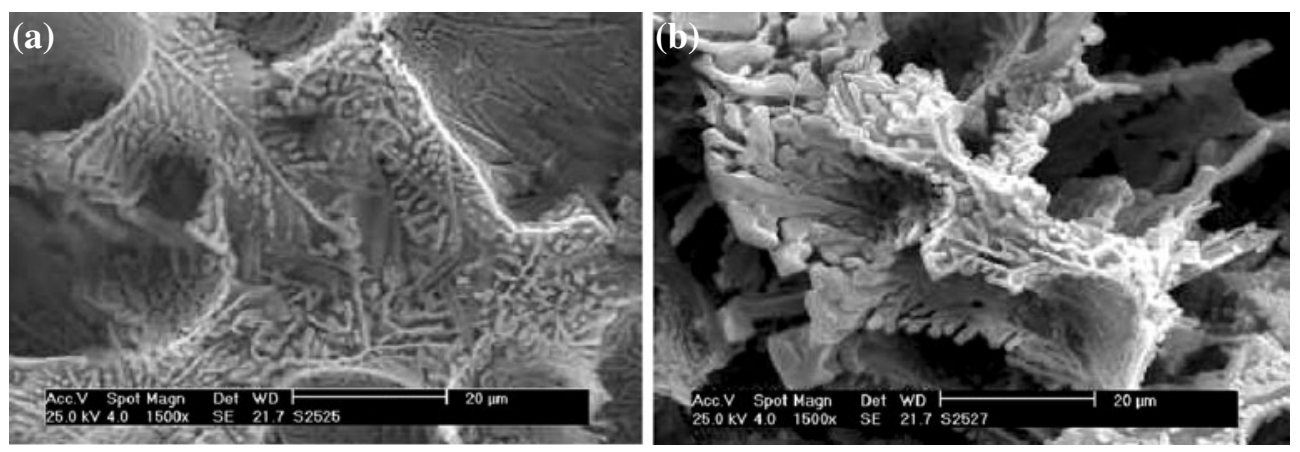

Figure 12. SEM micrographs of specimens with Bi/Sr ratio of (a) 2.3 and (b) 4 in stainless steel mould.

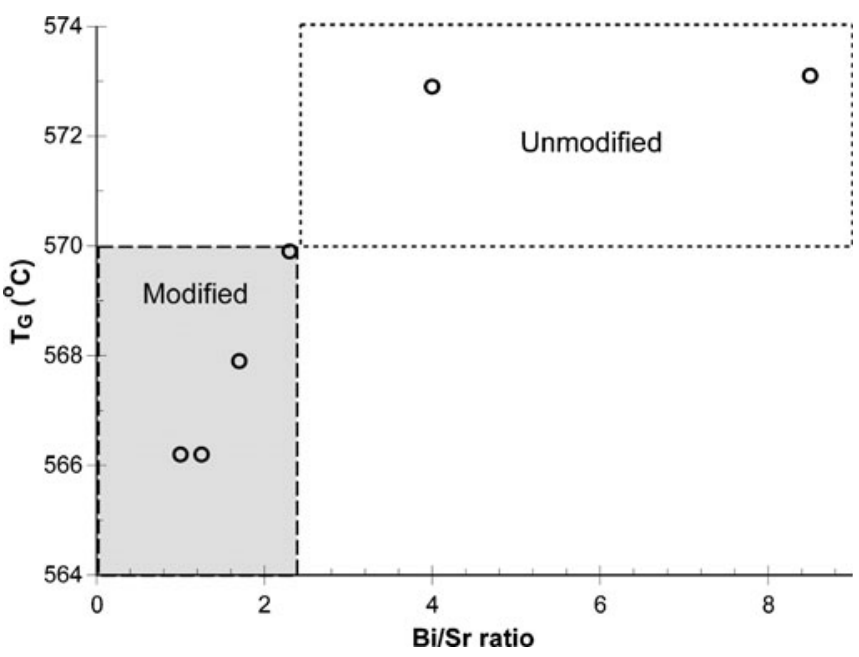

Figure 13. Relationship among $\mathrm{Bi} / \mathrm{Sr}$ ratio, $T_{\mathrm{G}}$ and silicon morphology.

silicon is finer compared with the slowly cooled specimens shown in figure 9. This fact is attributed to increased solidification rate which intensifies refinement of the structure. It can be seen that silicon eutectic morphology changed into plate structure when the ratio increased to $8 \cdot 5$. In addition, SEM micrographs in figure 12 confirm the fibrous to platelike transition with increasing $\mathrm{Bi} / \mathrm{Sr}$ ratio in the fast cooled samples.

A comparison between results of thermal and microstructural analysis shows that with increasing $\mathrm{Bi} / \mathrm{Sr}$ ratio, eutectic growth temperature increased and recalescence decreased. These results are reconciled well to the change in silicon structure from fibrous to plate-like. Furthermore, the relationship between the $\mathrm{Bi} / \mathrm{Sr}$ ratio, eutectic temperature and silicon structure is also plotted in figure 13 where it can be observed that at $\mathrm{Bi} / \mathrm{Sr}$ ratios below 2.3 the eutectic structure was modified and the eutectic temperature was below $569.9^{\circ} \mathrm{C}$. It is also seen that with increasing $\mathrm{Bi} / \mathrm{Sr}$ ratio of higher than 2.3 the eutectic temperature increased up to $573 \cdot 1{ }^{\circ} \mathrm{C}$ and the silicon eutectic structure displays a flake-like morphology typical of unmodified alloy.
Based on these observations, it can be concluded that with increasing $\mathrm{Bi} / \mathrm{Sr}$ ratio, from 1 to $8 \cdot 5$, the modification effect of strontium was continuously nullified, plate-like eutectic silicon appeared and the modification effect was completely eliminated. The results of the present study are in good agreement with previous findings which have reported that $\mathrm{Sr}$ modification effect was reduced with addition of $0.1 \% \mathrm{Bi}$ in A536.2 (Cho and Loper 2000) and $0.225 \mathrm{wt} \%$ Bi addition in 319 alloy (El-Hadad et al 2004). On the other hand, comparison of the microstructures in figures $9 \mathrm{~b}$ $(\mathrm{Bi} / \mathrm{Sr}=1.7)$ and $9 \mathrm{~d}(\mathrm{Bi} / \mathrm{Sr}=8 \cdot 5)$ and also their corresponding thermal analysis in figure 5 in which the same amount of $\mathrm{Bi}$ is added to the melt but with different $\mathrm{Sr}$ contents indicates that more $\mathrm{Sr}$ is required to neutralize the poisoning effect of $\mathrm{Bi}$ on $\mathrm{Sr}$ modification in bismuth-containing $\mathrm{Al}-\mathrm{Si}$ alloys.

The poisoning mechanism is not completely established, however, it has been suggested that there was a possibility that binary $\mathrm{Bi}_{3} \mathrm{Sr}, \mathrm{BiSr}$ and $\mathrm{Bi}_{2} \mathrm{Sr}_{3}$ or ternary $\mathrm{Bi}_{2} \mathrm{Mg}_{2} \mathrm{Sr}$ compounds might form before eutectic nucleation, leading to a reduction in the amount of free $\mathrm{Sr}$ available for modification (Cho and Loper 2000; Mohamed et al 2009). 


\section{Conclusions}

The major conclusions and suggestions drawn from this work are as follows:

Thermal analysis results showed that with increasing $\mathrm{Bi} / \mathrm{Sr}$ ratio, eutectic growth temperature increased to $573^{\circ} \mathrm{C}$ and recalescence decreased to $0 \cdot 2^{\circ} \mathrm{C}$ as in untreated alloys. Furthermore, microstructural observations showed a good correlation with thermal analysis results. Fibrous to plate-like transition in eutectic Si morphology confirmed thermal analysis results and indicated the poisoning effect of $\mathrm{Bi}$ on $\mathrm{Sr}$ modification in slow and fast cooling rates. At $\mathrm{Bi} / \mathrm{Sr}$ ratios below 2.3 the eutectic structure was modified and the eutectic temperature was below $569.9^{\circ} \mathrm{C}$. Likewise, with more than $2.3 \mathrm{Bi} / \mathrm{Sr}$ ratios, the eutectic structure was unmodified and the eutectic temperature increased up to $573 \cdot 1^{\circ} \mathrm{C}$. More $\mathrm{Sr}$ was needed to neutralize the poisoning impact in alloys containing bismuth.

\section{Acknowledgements}

The authors would like to acknowledge Universiti Teknologi Malaysia for providing research facilities and the Ministry of Science and Technology of Malaysia for financial support under vote. 79352.

\section{References}

Apelian D, Sigworth G K and Whaler K R 1984 AFS Trans. 92297 Cho J I and Loper C R 2000 AFS Trans. 108359
Djurdjevic M, Jiang H and Sokolowski J 2001 Mater. Charact. 46 31

El-Hadad S, Samuel A M, Samuel F H, Doty H W and Valtierra S 2004 AFS Trans. 112141

Elliot R 1983 Eutectic solidification processing (London, UK: Butterworths \& Co.)

Emadi D, Whiting L V, Nafisi S and Ghomashchi R 2005 J. Therm. Anal. Calorim. 81235

Farahany S, Ourdjini A, Idris M H and Thai T 2011 Trans. Nonferrous Met. Soc. China 211455

Golbahar B, Samuel F H, Samuel A M, Doty H W and Valtierra S 2007 AFS Trans. 11507

Gruzleski J E and Closset B M 1990 Treatment of liquid aluminiumsilicon alloys (IL, USA: Americans Foundrymen's Society Inc.)

Hegde S and Narayan Prabhu K 2008 Mater. Sci. 433009

Heusler L and Schneider W 2002 Light Met. 217

Hosch T, England L G and Napolitano R E 2009 Mater. Sci. 444892

Knuutinen A, Nogita K, McDonald S D and Dahle A K 2001 Light Met. 1229

Loper C R, Seong H G and Cho J I 2001 AFS Trans. 1091

Lu S Z and Hellawell A 1987 Metall. Trans. A18 1721

Machovec C J, Byczynski G E, Zindel J W and Godlewski L A 2000 AFS Trans. 108439

Mohamed A M A, Samuel F H, Samuel A M and Doty D H W 2009 Metall. Mater. Trans. A40 240

Nogita K, Knuutinen A, McDonald S D and Dahle A K 2001 Light Met. 1219

Pan E N, Cherng Y C, Lin C A and Chiou H S 1994 AFS Trans. 102 609

Pillai N P and Anantharaman T R 1968 Trans. Metall. Soc. AIME 242025

Qiyang L, Qingchun L and Qifu L 1991 Acta Met. 392497

Talbot D E J and Ransley C E 1997 Metall. Mater. Trans. A8 1149

Wang W and Gruzleski J E 1990 AFS Trans. 98227 